\title{
Muerte súbita debida a puente arterial coronario.
}

\author{
Sudden death due to coronary artery bridging.
}

\section{J. Blanco Pampín y cols. \\ Cuad Med Forense 2000;19:43-47}

Varón de 27 años, albañil, casado, sin antecedentes familiares o personales de interés. Fue encontrado muerto en la huerta de su casa donde instantes antes había estado talando árboles con un hacha. En el estudio necrópsico destacaba: corazón con un peso de 329 g, la arteria coronaria descendente anterior, en su primera porción, se incurvaba hacia el interior del septo interventricular, situándose a I cm de profundidad de la superficie epicárdica (Figura I) durante unos 3-4 cm, para salir de nuevo a la superficie y continuar su trayecto por la superficie epicárdica (puente coronario). El examen microscópico reveló extensas zonas de fibrosis intersticial en el territorio dependiente de la arteria coronaria descendente anterior. Se realizó estudio inmunohistoquímico usando anticuerpos antifibropectina y antifibrinógeno (marcadores de isquemia miocárdica precoz) mediante la técnica del complejo avidina-biotina-peroxidasa, apreciándose inmunotinción positiva en el núcleo y el citoplasma de numerosas fibras musculares cardíacas en el área dependiente de dicha arteria, especialmente en la pared anterior del ventrículo izquierdo (Figuras 2 y 3).

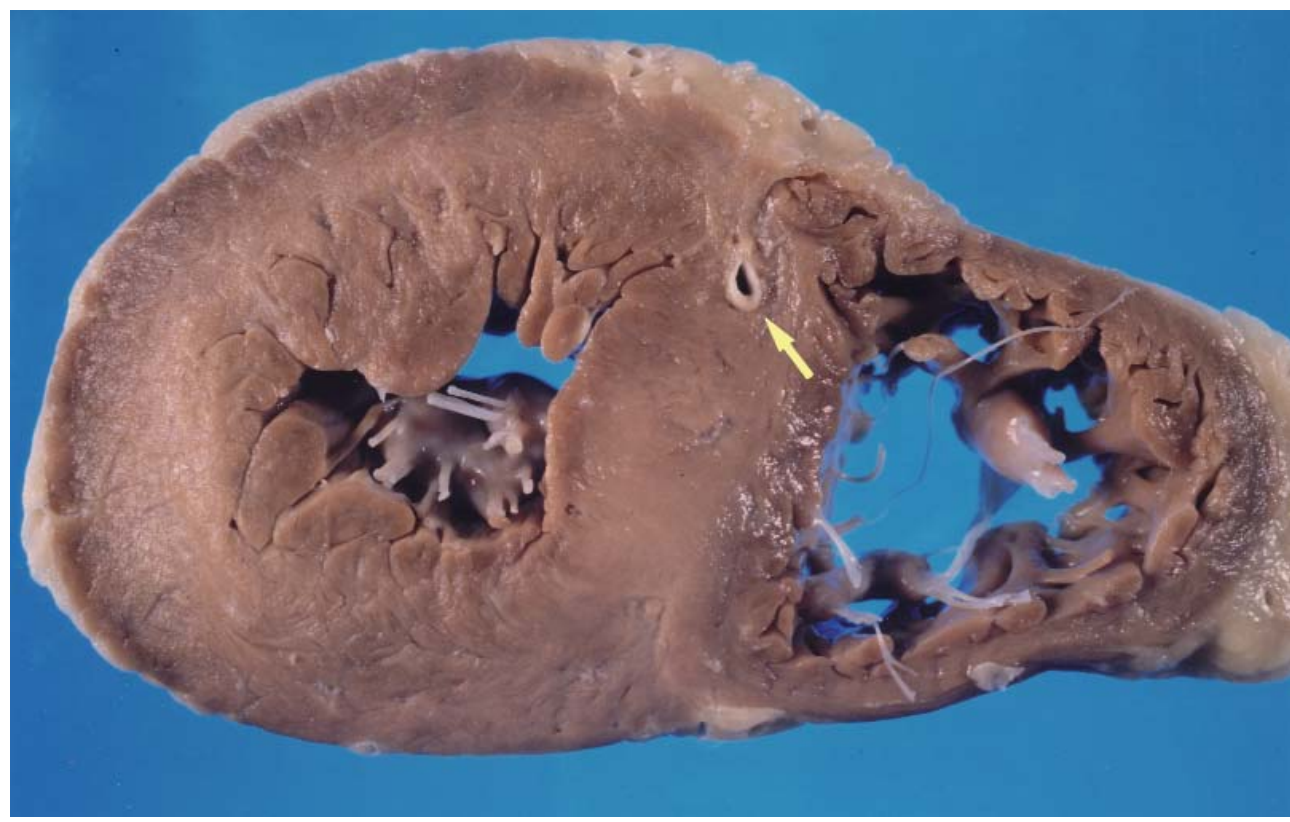

Figura 1.- Corte transversal de ambos ventrículos, apreciándose el trayecto intramiocárdico de la arteria coronaria descendente anterior (flecha). 


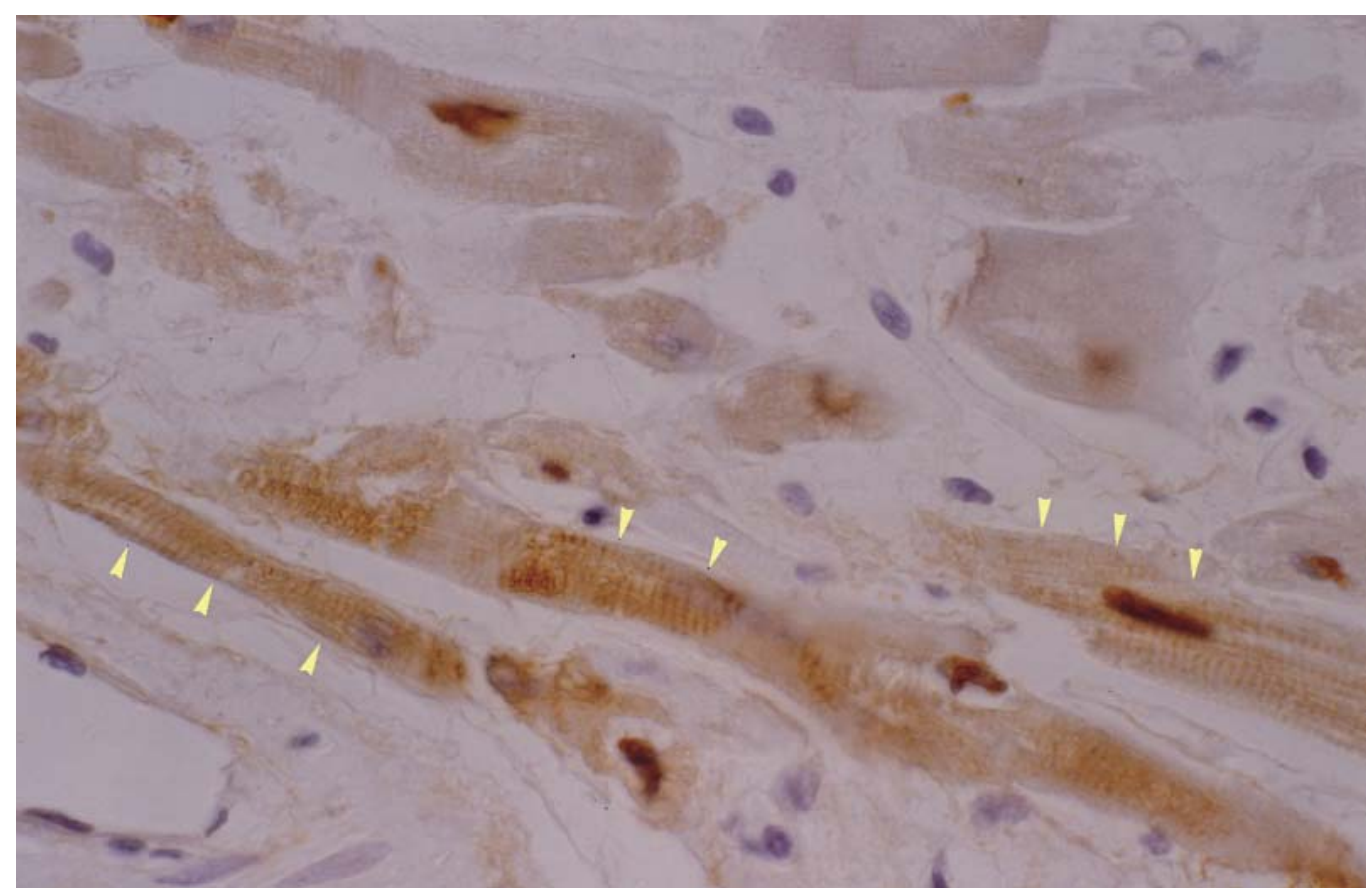

Figura 2.- Fibronectina en el interior de la fibra muscular cardiaca (flechas), indicativa de lesión isquémica irreversible (60x).

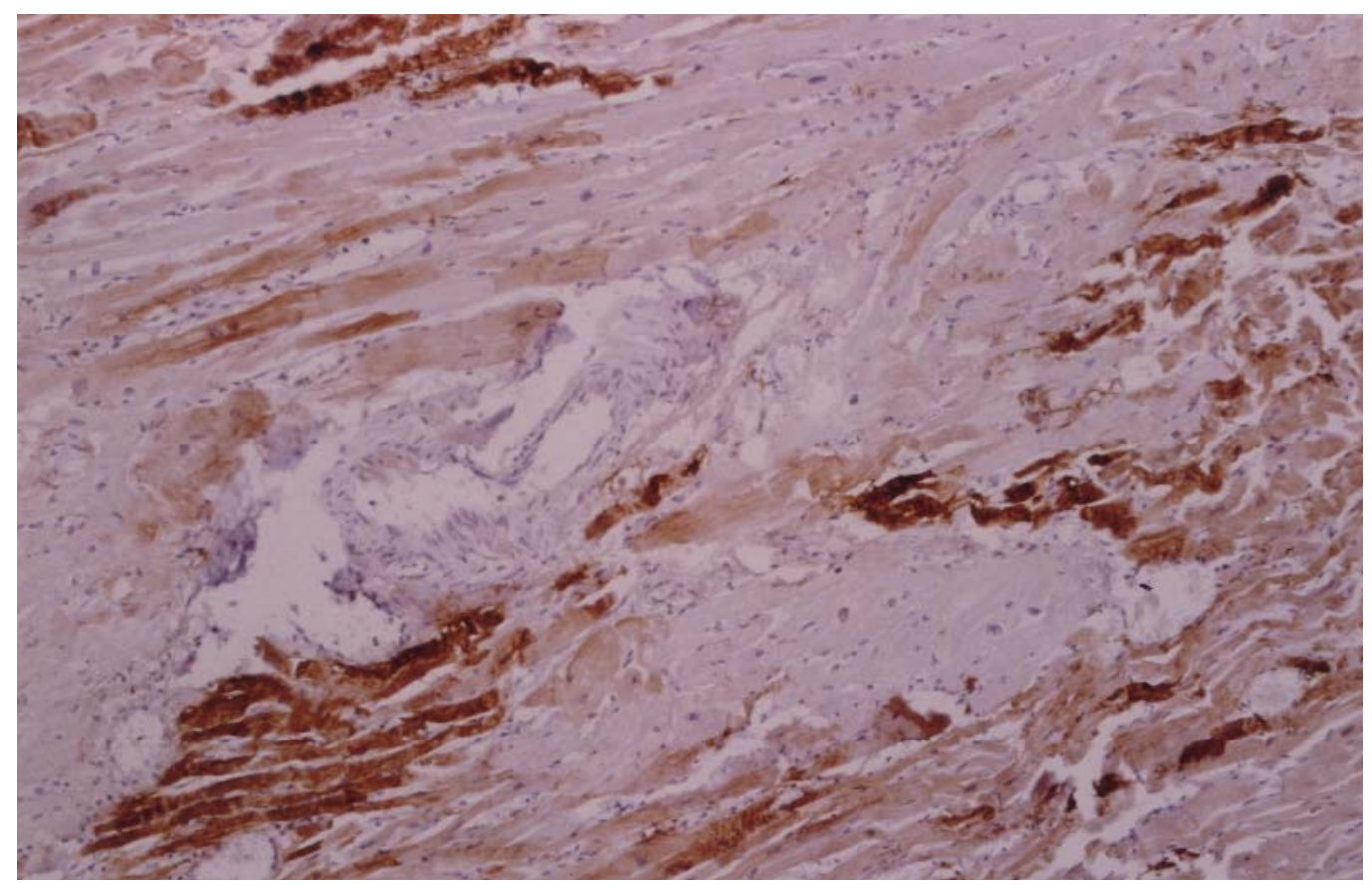

Figura 3.- Necrosis miocárdica. Inmunotinción positiva para anticuerpos antifibrinógeno (20x). 